$\mathbf{R}_{\text {ESEARCH }} \mathbf{P}_{\text {APER }} \longrightarrow$ FOOD SCIENCE e ISSN-2230-9403 - Visit us :

www. researchjournal.co.in

Volume 9 | Issue 1 | April, 2018 | 143-149

DOI : 10.15740/HAS/FSRJ/9.1/143-149

\title{
Elimination of sugar rich confectioneries in children with ADHD symptomatology
}

\author{
G.K. Beela and V.R. Raji
}

Learning disabilities such as Attention Deficit Hyperactivity Disorder (ADHD) which is also a neurobehavioral disorder are increasing and are currently drawing concern. This study is a randomised controlled trial into the effect of elimination of sugar rich confectioneries diet on the behaviour of a random group of school going children who meet the DSM IV criteria for ADHD. The recent controlled studies on nutrition and ADHD recommends that diets to reduce symptoms associated with ADHD include sugar restricted additive and preservative free, oligoantigene and elimination diet. In the present study a questionnaire consisting of 25 questions in the form of five scale rating was administered to the subjects in six sessions to determine the prevalence of ADHD symptoms during the diet intervention with elimination of sugar rich confectioneries diet. Fifty children of the age group of 4-12 years with ADHD symptoms were selected. Experimental group consisted of 30 children and Control group consisted of 20 children. Experimental group underwent diet interventions and counselling in six sessions whereas the Control group were not subjected to diet intervention. Statistical analysis was carried out using ANOVA and $\mathrm{T}$ test to compare the pre and post intervention scores and the scores of the experimental and control group. This study establishes that elimination of sugar rich confectionaries like chocolates, bakery confectionaries and soft drinks in the diet and replacing with highly nutritive value foods as per the RDA can reduce the ADHD symptoms in school going children of age group 4-12.

Key Words : ADHD - Attention deficit hyperactivity disorder, Diet intervention, DSM IV criteria, Sugar enriched confectionaries, Diet elimination, ADHD symptoms

How to cite this article : Beela, G.K. and Raji, V.R. (2018). Elimination of sugar rich confectioneries in children with ADHD symptomatology. Food Sci. Res. J., 9(1): 143-149, DOI : 10.15740/HAS/FSRJ/9.1/143-149.

\footnotetext{
Author for correspondence :

G.K. Beela, Department of Home Science, Kerala Agricultural University, Centre for Disability Studies, Poojapura, Thiruvananthapuram (Kerala) India (Email : beela.gk@kau.in)

Associate Authors' :

V.R. RAJI, Centre for Disability Studies, Poojapura, Thiruvananthapuram (Kerala) India (Email : rajirajesh2007206@gmail.com)
} 